\title{
Effect of Thermal Fatigue Property of Hot Strip Mill Work Roll Materials on the Rolled-in Defects in the Ultra-low Carbon Steel Strips
}

\author{
Jae-Hwa RYU and Han-Bin RYU \\ Hot Rolling Department, Pohang Works, POSCO, Pohang PO Box 36, 1 Koedong-dong, Nam-ku, Pohang-shi, Kyungbuk, 790- \\ 785, Korea. E-mail: jaeryu@posco.co.kr
}

(Received on April 23, 2002; accepted in final form on January 18, 2003)

\begin{abstract}
This work was carried out to prevent the rolled-in defects originated from the roll surface deterioration through the investigation of the effect of the thermal fatigue property of hot strip mill work roll materials on the roll surface deterioration and subsequent surface defects in the cold-rolled ultra-low carbon steel strips. The thermal fatigue property was estimated by conducting the thermal fatigue test for an existing nickelgrain iron and a candidate high speed steel in the temperature range of 200 to $600^{\circ} \mathrm{C}$, and its result was interpreted on the base of the microstructures, the mechanical and physical properties of the roll materials. It was found that the high speed steel had much better thermal fatigue property than the nickel-grain iron, which was attributed to a lower carbide content, a higher tensile and compressive strength and a higher thermal conductivity. And then, the effect of the roll materials on the rolled-in defects in the ultra-low carbon steels was investigated by inspecting the work roll surface deterioration in actual hot strip mill and subsequent surface defects in cold-rolled strips. The high speed steel roll with an excellent thermal fatigue property showed much higher resistance against roll surface deterioration than the nickel-grain iron roll, which led to prevention of the surface defects in the cold-rolled ultra-low carbon steel strips.
\end{abstract}

KEY WORDS: rolled-in defects; ultra-low carbon steel; hot strip mill work roll; thermal fatigue property.

\section{Introduction}

The production of the cold-rolled ultra-low carbon steel strips containing carbon content of less than $0.007 \%$ has greatly increased owing to high demands for good formable steels. The ultra-low carbon steel strips require severe surface quality as well as excellent formability because most of them are being used for the outer panels of automobile and home appliance. However, the tiny rolled-in type surface defects containing nickel, chromium, silicon as shown in Fig. 1 were often detected in the cold-rolled strips, which was thought to be caused by the surface deterioration of the nickel-grain work roll being used in the rear finishing stands of hot strip mill. ${ }^{1)}$ The surface deterioration of hot strip mill work rolls is generally known to be due to the thermal fatigue damage from the repeated heating and cooling cycle on the roll surface, ${ }^{2-4)}$ and it would be accelerated due to a higher rolling temperature when rolling the ultralow carbon steels.

Therefore, this work was conducted to reduce the surface defects by studying the effect of the thermal fatigue property of the roll materials on the roll surface deterioration and subsequent rolled-in defects in the cold rolled ultra-low carbon steel strips.
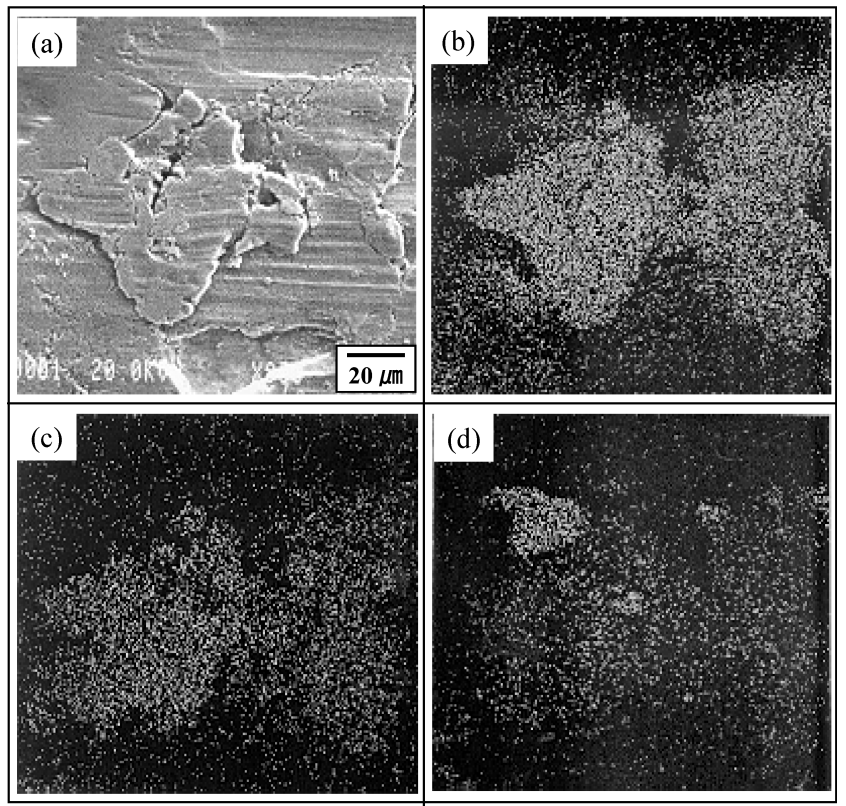

Fig. 1. The surface defect and its elemental mapping in the coldrolled ultra-low carbon steel. (a) SEM image, (b) nickel, (c) silicon, (d) chromium. 
Table 1. Chemical compositions of the roll materials used for thermal fatigue testing.

\begin{tabular}{|c|c|c|c|c|c|c|c|c|}
\hline \multirow{2}{*}{ Roll material } & \multicolumn{7}{|c|}{ Chemical composition (wt\%) } \\
\cline { 2 - 10 } & $\mathrm{C}$ & $\mathrm{Si}$ & $\mathrm{Mn}$ & $\mathrm{Cr}$ & $\mathrm{Ni}$ & $\mathrm{Mo}$ & $\mathrm{V}$ & $\mathrm{W}$ \\
\hline Nickel-grain iron & $2.8 / 3.5$ & $0.5 / 1.5$ & $0.5 / 1.0$ & $1 / 3$ & $3 / 5$ & $0.1 / 0.5$ & - & - \\
\hline High speed steel & $1.0 / 2.5$ & $0.5 / 1.6$ & $0.5 / 1.5$ & $4 / 7$ & $1 / 4$ & $1 / 4$ & $3 / 7$ & $0 / 5$ \\
\hline
\end{tabular}

\section{Experiments}

\subsection{Thermal Fatigue Testing}

Thermal fatigue testing was conducted for the nickelgrain iron and the high speed steel by using 10 ton thermal fatigue tester. ${ }^{5)}$ The testing samples were obtained from the outer shell of the centrifugally cast rolls, and then machined into a solid cylindrical type specimen with gauge length of $18 \mathrm{~mm}$ and diameter of $8 \mathrm{~mm}$. Their chemical compositions were listed in Table 1, respectively.

The maximum testing temperature was varied in the ranges of 400 to $600^{\circ} \mathrm{C}$ with a fixed minimum temperature of $200^{\circ} \mathrm{C}$. The test was conducted under total strain of $0 \%$ because the thin surface layer of the work roll which experiences the thermal fatigue is in a complete constraint by the roll interior. ${ }^{4,6)}$ The fatigue life was defined as the number of cycles to the complete failure. In order to interpret the thermal fatigue test results, the microstructure was examined by using an optical microscope and the fatigue crack initiation site was investigated by sectioning the fractured specimens longitudinally. In addition, in order to evaluate the thermal fatigue property of roll materials using the Eichelberg quality factors, the tensile strength, Vickers hardness and thermal expansion coefficient were measured. Tensile test was carried out at $200^{\circ} \mathrm{C}$ under tensile speed of $5 \mathrm{~mm} / \mathrm{min}$ by using the thermal fatigue tester. Vickers hardness for the matrix was measured over room temperature to $600^{\circ} \mathrm{C}$ under a load of $50 \mathrm{~g}$. The thermal expansion coefficient was also measured by using a transformation dilatometer.

\subsection{Mill Trials}

The effect of the roll materials on the roll surface deterioration of the rear finishing stands was investigated by interrupting the hot rolling practice intermediately in a rolling campaign including the ultra-low carbon steels, and then examining the roll surface. Subsequent rolled-in defects in the cold-rolled ultra-low carbon strips of $0.7 \mathrm{~mm}$ thickness were inspected in the recoiling line. The thickness of the strip was reduced from 36 to $3.0 \mathrm{~mm}$ in the hot-rolling finishing stands, and further reduced into $0.7 \mathrm{~mm}$ in the coldrolling stands. Hot rolling speed was $600 \mathrm{mpm}$, the finishing delivery temperature was $920^{\circ} \mathrm{C}$. In order to quantify the roll material effect, the grades of the roll surface deterioration and the surface defect were ranked on the base of the peeled area of the roll surface in the rear stands and length of the surface defects in the cold-rolled strips as listed in Table 2 and Table 3, respectively.

\section{Results and Discussion}

\subsection{Thermal Fatigue Property of the Roll Materials}

Figure 2 shows the fatigue life for two roll materials with the maximum testing temperature. At a given tempera-
Table 2. The grade of the roll surface peeling in the rear finishing stands.

\begin{tabular}{|c|c|}
\hline Grade & Appearance of the roll surface \\
\hline 0 & Newly ground and no deterioration \\
\hline 1 & Peeled area/total working zone $<10 \%$ \\
\hline 2 & $10 \% \leq$ peeled area/total working zone $<40 \%$ \\
\hline 3 & $40 \% \leq$ peeled area/total working zone \\
\hline
\end{tabular}

Table 3. The grade of the surface defect in the cold-rolled ultra-low carbon steel strips.

\begin{tabular}{|c|c|}
\hline Grade & Appearance of the strip surface \\
\hline 0 & No defect \\
\hline 1 & Defect length $<2 \mathrm{~mm}$ \\
\hline 2 & $2 \mathrm{~mm} \leq$ defect length $<5 \mathrm{~mm}$ \\
\hline 3 & $5 \mathrm{~mm} \leq$ defect length \\
\hline
\end{tabular}

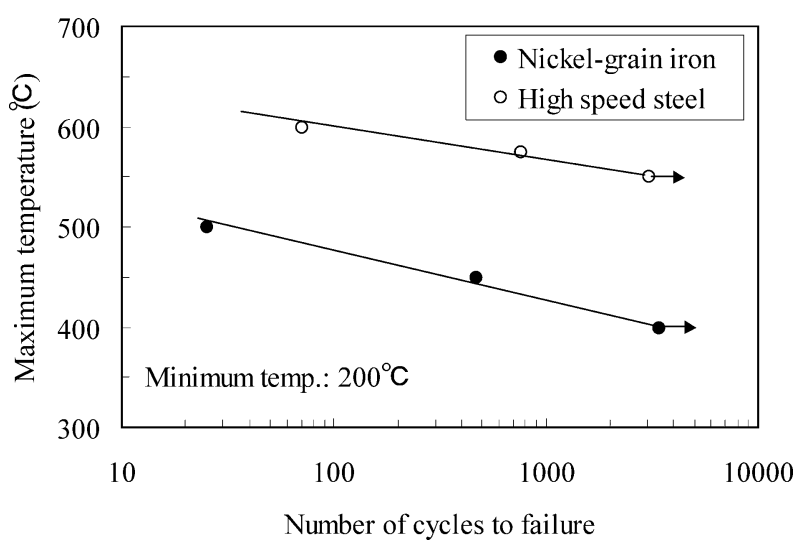

Fig. 2. Variation of thermal fatigue life with the maximum temperature in the roll materials.

ture, the high speed steel had much longer fatigue life than the nickel-grain iron. The fatigue life was greatly shortened with increasing the maximum temperature due to an increased thermal stress.

Thermal fatigue property of the roll materials is determined by the collective effect of their microstructures, mechanical and physical properties, therefore, the thermal fatigue test result is interpreted by focusing on these factors.

Figure 3 shows the microstructures of the high speed steel and the nickel-grain iron, respectively. The microstructures of both roll materials are composed of a tempered martensitic matrix (grey region) and the carbides (white region), but the nickel-grain iron contains a few percent of graphites (black region). The high speed steel has finer carbides and much less amount of carbides than the nickel-grain iron due to a lower carbon content as shown in Table 1.

Figure 4 shows the sectioned surface of the thermal-fatigued specimens. The coarse carbides existing on the specimen surface acted as the preferred crack initiation sites because they had low ductility as well as a large difference in 
thermal expansion coefficient with the matrix.

Figure 5 shows the density of the fatigue cracks on the surface of the thermal-fatigued specimens. The high speed steel had lower crack density than the nickel-grain iron, which is mainly attributed to a lower amount of carbides and finer carbides. The density of the fatigue cracks increased with raising the maximum temperature from a higher thermal stress. From the microstructural point of view, it is thought that the high speed steel has higher ther-

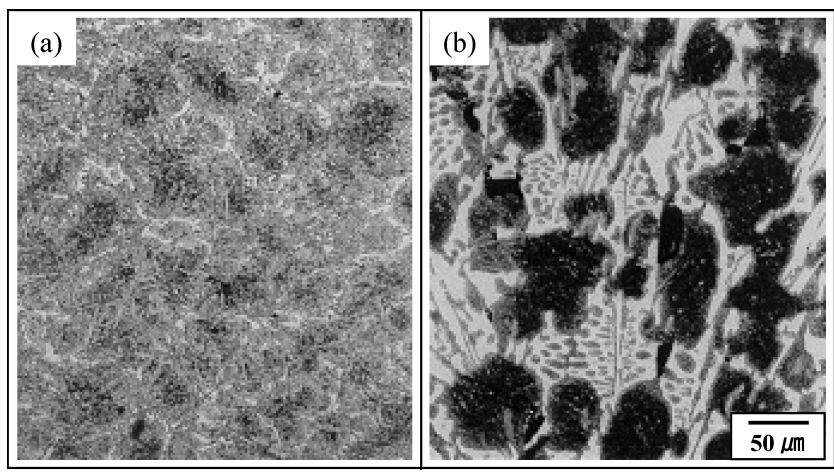

Fig. 3. Optical microstructures of the roll materials. (a) High speed steel, (b) nickel-grain iron.

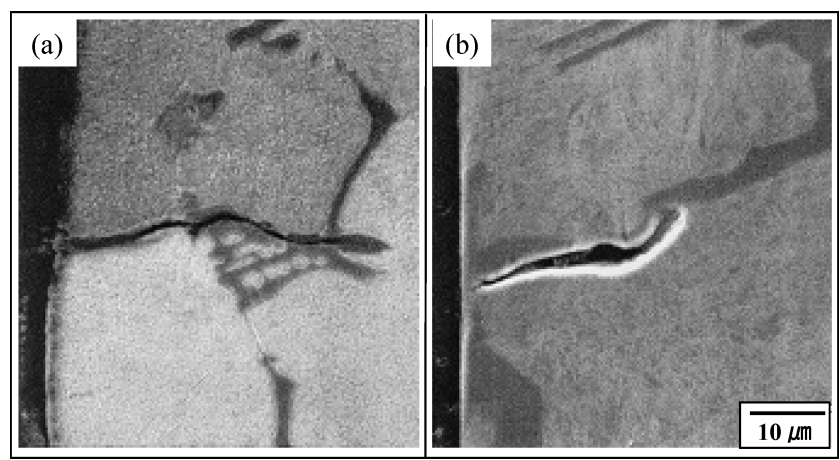

Fig. 4. Surface cracks on the thermal-fatigued specimens. (a) High speed steel, (b) nickel-grain iron.

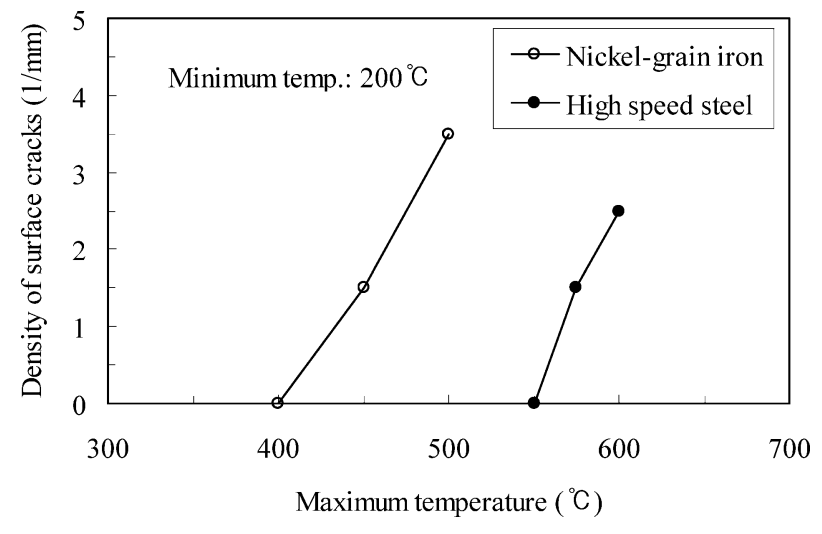

Fig. 5. Variation of the surface crack density with temperature in the thermal fatigued specimens. mal crack resistance than the nickel grain iron.

The mechanical properties to affect the thermal fatigue property of the roll materials are the compressive yield strength at high temperature and the tensile strength at an ambient temperature because the plastic strain is mainly developed under compressive load at high temperature and fatigue failure is taken place under tensile load. ${ }^{5)}$ The compressive yield strength could be inferred from the variation of hardness with temperature. As shown in Fig. 6, the high speed steel has much higher hardness than the nickel-grain iron at all testing temperature ranges, which means that the compressive yield strength of the high speed steel is much greater than that of the nickel-grain iron at high temperature. The tensile strength was measured to be $960 \mathrm{MPa}$ for the high speed steel and $510 \mathrm{MPa}$ for the nickel-grain iron at $200^{\circ} \mathrm{C}$, respectively. The lower tensile strength of the nickel-grain iron is related with an existence of flake-type graphites that act as notches under tensile load. ${ }^{7}$ Therefore, an excellent mechanical property of the high speed steel would bring about a higher plastic deformation resistance during thermal cycling, which leads to a longer thermal fatigue life.

The physical properties to influence thermal fatigue property are thermal expansion coefficient, thermal conductivity and Young's modulus, but these effects are inter-related with not only each other but also the mechanical property. The collective effects of the mechanical and physical properties on the thermal fatigue properties can be described as Eichelberg quality factor ${ }^{8)}$ :

$$
\text { Eichelberg quality factor }=\frac{(1-v) \cdot k \cdot \sigma_{\mathrm{u}}}{E \cdot \alpha}
$$

Where, $v$ : Poisson's ratio, $k$ : thermal conductivity, $\sigma_{\mathrm{u}}$ : tensile strength at an ambient temperature, E: Young's modulus, $\alpha$ : thermal expansion coefficient.

The calculated values of Eichelberg quality factor for two roll materials are listed in Table 4. The high speed steel has much higher value than the nickel-grain iron, which is

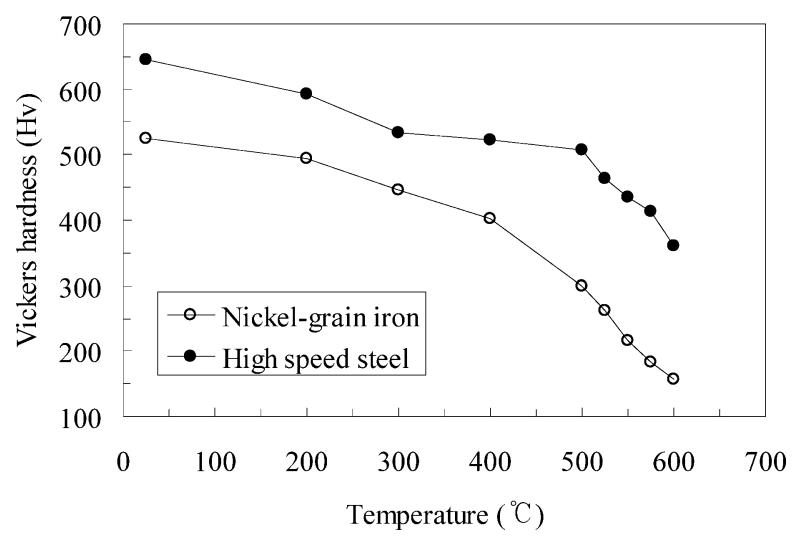

Fig. 6. Variation of the hardness of the roll materials with temperature. (load: $50 \mathrm{~g}$ )

Table 4. Mechanical and physical properties, and the calculated Eichelberg quality factor of the roll materials.

\begin{tabular}{|c|c|c|c|c|c|c|}
\hline Roll material & $v^{*}$ & $\begin{array}{c}\mathrm{k}^{*} \\
(\mathrm{~W} / \mathrm{m} \cdot \mathrm{k})\end{array}$ & $\begin{array}{c}\sigma_{\mathrm{u}} \\
(\mathrm{MPa})\end{array}$ & $\begin{array}{c}\mathrm{E}^{*} \\
(\mathrm{MPa})\end{array}$ & $\begin{array}{c}\alpha \\
\left(10^{-6} / \mathrm{k}\right)\end{array}$ & $\begin{array}{c}\text { Eichelberg } \\
\text { quality factor }\end{array}$ \\
\hline Nickel-grain iron & 0.27 & 23.5 & 510 & 175000 & 14.5 & 3448 \\
\hline High speed steel & 0.27 & 25.5 & 960 & 235000 & 14.0 & 5432 \\
\hline
\end{tabular}

* : Reference 9 


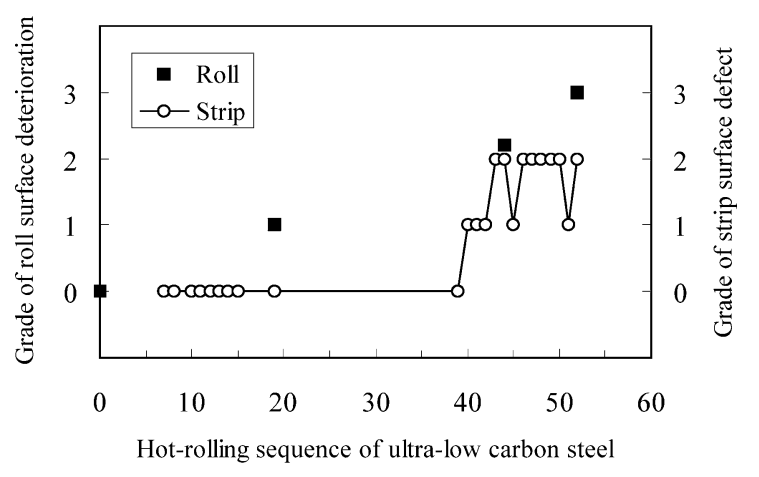

(a)

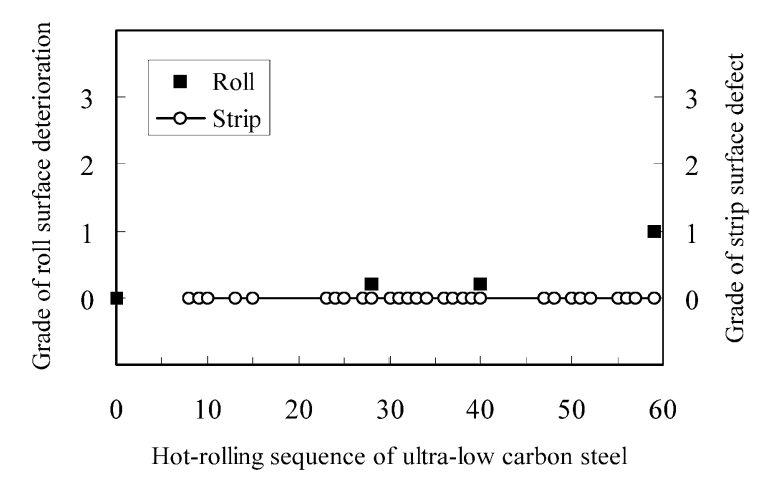

(b)

Fig. 7. Effect of the hot-rolling sequence of the ultra-low carbon steel on the roll surface deterioration and the surface defect of the cold-rolled strips for two roll materials: (a) nickel-grain iron roll, (b) high speed steel roll.

mainly due to a higher tensile strength and a higher thermal conductivity.

From the results above mentioned, it is clear that the high speed steel has much better thermal fatigue property than the nickel-grain iron as shown in Fig. 2.

\subsection{The Results of Mill Trials}

Figure 7 shows the relation of the hot-rolling sequence of the ultra-low carbon steels with the surface deterioration of the rear finishing work rolls and subsequent rolled-in de- fects in the cold-rolled strips for two roll materials. It was found that the high speed steel roll with an excellent thermal fatigue property had much higher resistance against the roll surface deterioration than the nickel-grain iron roll, and then led to a good surface quality in the cold-rolled strips. The roll surface deterioration gets worse in the latter part of a rolling campaign, which is attributed to an accumulated thermal fatigue damage.

From the results of thermal fatigue test and mill trials, it was decided to introduce the high speed steel roll into the rear stands when rolling the ultra-low carbon steels. Consequently, the complete prevention of the rolled-in surface defects was achieved.

\section{Conclusions}

(1) The high speed steel had much better thermal fatigue property than the nickel-grain iron because it had a lower carbide content, a higher tensile and compressive strength and a higher thermal conductivity.

(2) It was found that the surface deterioration of hot strip mill work rolls was directly related with the thermal fatigue property of the roll materials.

(3) The high speed steel roll showed much higher resistance against the roll surface deterioration than the nickelgrain iron roll due to an excellent thermal fatigue property, and then led to a good surface quality of the cold-rolled ultra-low carbon steel strips.

\section{REFERENCES}

1) T. Suminaga: CAMP-ISIJ, 6 (1993), 1328.

2) R. V. Williams and G. M. Boxall: J. Iron Steel Inst., 203 (1965), 369.

3) J. J. deBarbadillo and C. J. Trozzi: Iron Steel Eng., 58 (1981), 63.

4) J. H. Ryu, O. Kwon, P. J. Lee and Y. M. Kim: ISIJ Int., 32 (1992), 1221.

5) S. Lee, D. H. Kim, J. H. Ryu and K. Shin: Metall. Mater. Trans. A, 28A (1997), 2595.

6) A. A. Tseng, S. X. Tong, S. H. Malsen and J. J. Mills: J. Heat Transfer, 112 (1990), 301.

7) W. L. Bradley and M. N. Srinivasan: Int. Mater. Rev., 35 (1990), 129.

8) J. C. Radon, D. J. Burns and P. P. Benham: J. Iron Steel Inst., 204 (1966), 928.

9) M. Hashimoto, S. Otomo, K. Yoshida, K. Kimura, R. Kurahashi, T. Kawakami and T. Kouga: ISIJ Int., 32 (1992), 1202. 